\title{
Work-family conflicts of women in the Air Force: their influence on mental health and functioning
}

\author{
AMIRAM D. VINOKUR ${ }^{1 *}$, PENNY F. PIERCE ${ }^{2}$ \\ AND CATHERINE L. BUCK ${ }^{1}$ \\ ${ }_{1}^{1}$ Institute for Social Research, The University of Michigan, Ann Arbor, Michigan 48106-1248, U.S.A. \\ ${ }^{2}$ School of Nursing, The University of Michigan, Ann Arbor, Michigan 48109-0482, U.S.A.
}

\begin{abstract}
Summary This paper examined the effects of work and family stressors and conflicts on Air Force women's mental health and functioning. We analyzed data from a 1993 survey of representative stratified samples of 525 Air Force women from the active duty reserve and guard forces. The analyses of the data are guided by the comprehensive model of work-family conflict that has been tested by Frone, Russell, and Cooper (1992) using a large representative community sample. Structural equation modeling analyses provided support for the work-family conflict model. The analyses also provided support for an extension of the model, which included the separate effects of marital and parental roles on mental health. The extended model demonstrated that job and parental stresses had direct effects on work-family conflicts and that job and marital distress and familywork conflict had an independent adverse effect on mental health. Whereas job and parental involvement had a beneficial effect on distress, they had an adverse effect on work-family conflicts. Copyright (C) 1999 John Wiley \& Sons, Ltd.
\end{abstract}

\section{Introduction}

There is a continuing trend of growth in women's participation in the civilian labor market with women making up nearly 50 per cent of the labor market (U.S. Bureau of the Census, 1988). In addition, and compared to just two to three decades ago, women are more likely to combine their role as mothers with that of workers. By 1988, 57 per cent of married women with children under

\footnotetext{
* Correspondence to: Amiram D. Vinokur, Institute for Social Research, The University of Michigan, 426 Thompson Street, Ann Arbor, Michigan 48106-1248, U.S.A. E-mail: avinokur@umich.edu

Authors Note: This research was supported by a Tri-Service Nursing Research Program through USUHS Grant Number MDA 905-92-Z-0012 (Survey Control Number USAF SCN 93-48) of the Department of Defense and by the National Institute of Mental Health grant P30MH38330 to the Michigan Prevention Research Center. The opinions or assertions contained here are the private ones of the authors and are not to be construed as official or reflecting the views of the Department of Defense or the United States Air Force. We would like to thank Dr Michael R. Frone for making available the measuring instrument to test the work-family conflict model.
}

Contract grant sponsor: Tri-service Nursing Research Program, Department of Defence.

Contract grant number: MDA 905-92-Z-0012. 
the age of 6 were employed (U.S. Bureau of the Census, 1990). Studies of dual career families demonstrated that the women, while employed, continue to carry a larger share of the burden of house functions to maintain the household (Berardo, Shehan and Leslie, 1987). Even more remarkable are the findings reported by Biernat and Wortman (1991). In their study of married professional women who had relatively equal high status careers as their husbands, they found the same pattern of traditional inequity in the distribution of child-care tasks and chore responsibilities at home that disadvantaged the women. Further, the women were more selfcritical of their role performance in the home than their husbands. Thus, as the family remains an important central domain in women's lives and the importance of work as another domain is steadily growing so is the potential for conflicts between the roles played in these two domains. A growing number of policy and review articles focus on the increasing and changing role of women in the workplace and the consequences of these changes to their families, their mental and physical health and well being (Bielby, 1992; Matthews and Rodin, 1989; Menaghan, 1991; Repetti, Matthews and Waldron, 1989).

Recent empirical studies have already explored the possible work-family conflicts on women's coping strategies (Berardo et al., 1987; Wortman, Biernat and Lang, 1991) and their mental health and well-being (Barling and Macewen, 1992; Frone, Russell and Cooper, 1992; Lennon and Rosenfield, 1992). The conflicts between the demands in the domains of work and family are often hypothesized to result in spillover effects of the stress of work on family life and vice versa. In fact, a recent study by Adams, King and King (1996) demonstrated that when work interferes with family life it also reduces the satisfaction from job and from life as a whole.

Nowhere is the potential for a conflict between the demands of family and work greater than in the lives of women who serve in the armed forces. The armed forces constitute a total institution that views its demands as superseding any competing family or personal needs (Segal, 1986a, 1986b, 1989; Stanley, Segal and Laughton, 1990). Segal describes both work and family as 'greedy institutions', placing military women in a tenuous position of sacrifice and compromise between the two roles.

The demographics of today's military include a significant number of women, a large proportion of whom are with dependent children. Women represent 11 per cent of the active duty force and 13 per cent of the reserves. With a growing number of women in the armed forces (Holm, 1992; Schneider and Schneider, 1992), combined with an increase in their participation in traditional men's roles (U.S. Presidential Commission, 1993), family-work conflicts are expected to increase (Kupchella, 1993).

Although the impact of the stresses of military life has been studied in relation to fathers' absence during wartime (Jensen, Lewis and Xenakis, 1986; Wexler and McGrath, 1991) and the impact on the emotional and social adjustment of their wives and children (Bey and Lange, 1974; Dahl, McCubbin and Ross, 1975; MacIntosh, 1968), there is no comparable literature exploring the demands of a professional military career on the health and well-being of women and their families. In addition, there is no information on how military women reconcile the demands of family life with the extraordinary expectations of the role of a professional solider. The lifestyle of a military woman today is unpredictable and one in which she must maintain a state of readiness to respond to possible deployment, extended tours, or training away from home. Keeping the 'home fires' burning in her absence calls for extraordinary planning and multiple sources of support. Even while at home, military duties include long and unpredictable work hours, being on call for unexpected problems or emergencies, and meeting the expectation that the military mission comes first. The extraordinary expectations and demands placed on today's military woman, in concert with the traditional demands of marriage and parenthood, provide a useful arena for the study of these competing influences on mental health. In summary, the lives of 
women in the armed forces are filled with stressful job and family events that include frequent transfers, lengthy absences from family and children, and occasional threatening war conditions and experiences far from home. It is this context that precipitates stress and conflict and which also provides an ideal ground for testing theories of work-family conflicts.

The purpose of this paper is to examine the effects of work and family stressors on Air Force women's mental health. Examination of these issues was guided by the comprehensive model of work-family conflict that has been tested by Frone et al. (1992) using a large representative community sample. Frone and his associates constructed a work-family model with the goal of integrating research on work and on the family incorporating the interface in these domains. Thus, their model attempted to investigate not only the separate effects of work and family stressors on mental health but also the way these stressors create conflicts between the work and the family domains. In turn, these conflicts, which were described as work interference with family life (work-family conflict) or family life interference with work life (family-work conflict) were hypothesized to have direct adverse effects on the psychological distress (strain) that is experienced in each respective domain and also on mental health. Finally, the model postulated a bi-directional influence from work-family conflict to family-work conflict and vice versa. The model also incorporated level of involvement in each domain as a factor that decreases the distress level from stressful experiences in the domain but increases conflict between domains. (For a fuller account of the model and the literature that supports it see Frone et al., 1992.)

The work-family conflict model that was tested by Frone et al. however, did not provide a means for distinguishing the effects of parental role stressors from marital role stressors. We therefore extended the model by disentangling the global effect of family stress and included separate constructs to assess the effects that arise from the relationship with the spouse or a committed partner from these that arise from relationships, demands and responsibilities of raising children. This more elaborate model attempted to capture in greater detail the sources of work-family conflict spillover effects. Finally, whereas the model tested by Frone et al. focused exclusively on depressive symptoms as the sole mental health indicator, our tests of the original and the extended model also included a measure of role and emotional functioning. The inclusion of these two measures, depression and functioning, provides a more sound basis for examining the applicability of the models to general mental health versus the specific domain of experiencing depressive symptoms.

To pursue the examination of the issues described above we utilized data from a survey of representative stratified samples of Air Force women from the active force, the reserve and the guard who were activated for service during operations Desert Shield/Storm. As detailed below, whereas the information in the survey was collected during the summer of 1993, a little over two years after the end of Desert Shield/Storm operations, it focused on the women's current family and work situation.

\section{Method}

\section{Design and respondents}

A stratified sample of 638 women was drawn from the data base tape provided by the Department of Defense Manpower Data Center (DMDC) containing records for all 88,415 women who served in the Air Force either on active duty or were activated guard or reservists during the period of Desert Shield/Storm, that is, from August 1, 1990 to May 31, 1991. To achieve 
representativeness as well as obtain large enough subgroups for statistical analyses of particular interest, we applied random sampling procedure with oversampling from certain strata. Thus, the sampling frame was stratified on component of the Air Force (active duty 89 per cent, reserve 9 per cent, and guard 2 per cent), deployment (in theater of operations 7.5 per cent, elsewhere 92.5 per cent), and parental status (non-parents 55 per cent, parents 45 per cent). Our obtained sample consisted of 50 per cent active duty, 25 per cent reserve, and 25 per cent guard; 55 per cent non parents and 45 per cent parents as in the sample frame, and 33 per cent who were deployed to the theater of operations versus 66 per cent who served elsewhere during the same time period.

Of the 638 women sample, 525 (82 per cent) were located and provided data in one telephone interview and two successive self-administered questionnaires that were mailed to the respondents. Of those women who we were able to contact, 97 per cent provided us with both the telephone interview and the questionnaires. Of the 525 respondents who were interviewed, 370 (70.5 per cent) were enlisted and 155 (29.5 per cent) were officers. By May 1991, the respondents had served an average of $8.72(S . D .=5.38)$ years in the military. At the time of data collection (summer of 1993) 187 (36 per cent) were on active duty, 228 (44 per cent) were in the reserve/ guard, and 109 (20 per cent) had left the Air Force (about half classified as Inactive Reserve).

Demographically, the respondents' age ranged from 19 to 60 years of age with a mean of 33.9 $(S . D .=7.01)$. The mean number of years of education was $14.6(S . D .=1.9)$. Less than one per cent of the women had not completed high school, 22 per cent had completed high school, 37.1 per cent had some college education, 15.9 per cent completed college and 24.6 per cent had post graduate education. In terms of marital status, 110 (21 per cent) were never married, 287 (55 per cent) were married, 28 ( 5 per cent) were separated, 97 (19 per cent) were divorced, and 3 ( 0.6 per cent) were widowed. Of the 525 women, 298 (58 per cent) were also primary care providers with a mean of $1.74(S . D .=0.79)$ children. The median family income was U.S. $\$ 36,080$ per year. The racial or ethnic composition of the sample included 81 per cent Whites, 13 per cent African Americans/Blacks, 3 per cent Hispanics, and 3 per cent other minorities. Of the 337 women who were not on active duty, 222 (66 per cent) were employed in a civilian job.

\section{Data collection procedures}

Respondents were contacted via a letter describing the general purpose of the study and then were telephoned and completed a 25-minute interview. Immediately following the telephone interview, the respondents were mailed a package with two self-administered questionnaires. All the questionnaires were accompanied by a letter that explained the purpose of the study, informed the respondents that their participation was completely voluntary and that the data they provided would remain confidential. Respondents were also promised to be paid for their effort in providing the information in the telephone interview and in questionnaires.

Within one week of receiving the first completed questionnaire from each Air Force woman we mailed her the second self-administered questionnaire and attached a \$24 cheque payment ( $\$ 12$ for telephone interview, and $\$ 12$ for the first questionnaire). Upon returning the second completed self-administered questionnaire we mailed the additional \$12 check payment for that questionnaire.

Telephone interview was conducted by trained telephone interviewers using Computer Assisted Telephone Interviewing (CATI) to maximize the efficiency and accuracy of the interview. An important purpose of the telephone interview was to develop rapport with the respondents which would encourage them to continue to participate through the study. It allowed us to give 
more information about the study and to address the respondents questions and issues to be examined later in the study. In addition, the CATI system allows us to collect complicated data with many skip patterns that are not as accurate with self-administered questionnaires. The telephone interview included demographic and biographical questions on the respondents' location and participation in the Persian Gulf War.

The two questionnaires included questions which focused on the respondents' primary work, the military assignment for active duty respondents and the civilian job for reservists and guard members. It also included sections on the respondents' relationship with their husbands or significant others, parenting, personal health and well-being. They also contained a section on work oriented to the military work of reservists and guard members. It also contained sections on the children's life events and experiences during the war, and their well-being then and now, questions about attitude and intentions regarding re-enlistment and more questions about the military woman's health and well-being.

\section{Measures}

All of the constructs in this study were assessed with multi-item indices, and most had a Cronbach coefficient alpha (Nunnaly, 1978) in the 0.70s and 0.80s.

\section{Background measures}

Demographics were assessed using standard survey questions for reporting age, education, marital status, family income, occupation, race or ethnic identification, and more elaborate questions for reporting on children and the provision of primary care for them during their mothers' absence. Demographic information, as well as relevant biographical data regarding military status, was also available on the tape obtained from the data base tape provided by the DMDC.

Military status and background was determined from answers to a series of questions regarding the respondent's military experience, her status and job classification code at the time of deployment and at the present time, number of years of military service, and periods and places of activation and/or deployment during operations Desert Shield/Desert Storm.

\section{Measures of work experiences}

Job experiences and working conditions in military service were reported using the measures described below by all the women who were still (at the time of data collection) in military service. Using the same measures, job experiences and working conditions in civilian jobs were also reported by the women who were not serving on active duty, that is, by those who were on reserve, guard or those who had already left the armed forces. Thus, our measures provide both data on the primary job that combined the measures from the active duty women on their job in the military and the measures from all the other women on their job in civilian life, and additional data from the women in the reserve and guard on their secondary job, which was their job in the military. The following is the series of measures on job experiences and working conditions:

Job stress was measured with a 20 -item scale taken from previously published measures (see Frone et al., 1992). Factor analysis produced four subscales, including work overload (pressure), 
lack of autonomy, role ambiguity and lack of responsibility. The response scale for the items on the scale ranged from 1 (almost never or never) to 4 (almost always). Cronbach coefficient alpha was 0.83 .

Job distress was assessed using eight items of which six were developed by Kandel et al. (1985) and also used by Frone et al. (1992). The two additional items were added to represent aspects of distress in military jobs (feeling harassed, intimidated). The items assessed various daily emotional experiences on the job (e.g., relaxed, frustrated, upset). The 4-point response scale for these items ranged from 1 (not at all) to 4 (very). Cronbach coefficient alpha was 0.83 .

Job involvement was assessed with 5-item scale adapted by Frone et al. (1992) from a measure developed by Kanungo (1982). Job involvement items focused on the extent to which the job is central to one's self-concept or sense of identity and were answered on a 6-point agree/disagree response scale. Cronbach coefficient alpha was 0.90 .

\section{Measures of family life and work-family conflicts}

Family stress, distress and involvement were measures taken from Frone et al. (1992). Family stress was measured with one 2-item scale assessing marital stress (degree of tension or conflict in the relationship) and one 4-item scale assessing parental stress. The scales were based on items developed in a study by Kessler (1985) and by Frone et al. (1992). The marital and parental stress scales had Cronbach alpha coefficients of 0.73 and 0.68 , respectively. In a similar vein, family distress was measured using a 6-item scale assessing marital distress and another 6-item scale assessing parental distress. The scales were developed by Kandel et al. (1985) and assess the strength of emotional reactions (e.g., upset, frustrated) in day-to-day experiences with their spouse/partner or children. The marital and parental distress scales had Cronbach alpha coefficients of 0.87 and 0.77 , respectively. Finally, family involvement was again measured using one 5-item scale assessing marital involvement and one 5-item scale assessing parental involvement. The items of these scales were adapted from the job involvement items and were used successfully in previous work-family conflict research (e.g., Frone and Rice, 1987). The items included a 6-point rating scale ranging from 1 (disagree strongly) to 6 (agree strongly). The marital and parental involvement scales had Cronbach alpha coefficients of 0.90 and 0.83 , respectively. The indices of family stress, distress and involvement were created by taking the mean of the respective pair of marital and parental scales.

Work-family conflict included two scales developed and used by Frone et al. (1992). The workfamily conflict $(\mathrm{W} \rightarrow \mathrm{F})$ 2-item scale assessed the frequency with which the respondent's job interfered with family life, and the family-work conflict $(\mathrm{F} \rightarrow \mathrm{W})$ 2-item scale assessed the frequency that home life interfered with job responsibilities and work life. The work-family and family-work conflict scales had Cronbach alpha coefficients of 0.84 and 0.75 , respectively.

\section{Measures of mental health and well-being}

Depression was measured by assessing depressive symptoms using an 11-item scale based on the Hopkins Sympton Checklist (Derogatis et al., 1974). The 11-item scale required respondents to indicate how much $(1=$ not at all, $5=$ extremely) they had been bothered or distressed in the 
last two weeks by various depressive symptoms such as feeling blue, having thoughts of ending one's life, and crying easily. The Cronbach coefficient alpha of the scale was 0.86 .

Role and emotional functioning was measured with a 15-item index developed by Caplan et al. (1984). The items require the respondents to indicate '... how well have you been doing in the last two weeks with respect to ...' various role and emotional tasks such as handling responsibilities and daily demands, staying level-headed, making the right decisions, etc., on a 5 -point scale $(1=$ very poorly, $5=$ exceptionally well $)$. The scale's Cronbach coefficient alpha was 0.94 .

\section{Response rate and analysis of attrition bias}

Of the 638 Air Force women sampled we were able to contact 542 ( 85 per cent) for solicitation into the study, and 525 ( 82 per cent) became study participants who provided data for the study. (Of those contacted only 17 (3 per cent) refused to participate.) The sample of 638 women was drawn from the data-tape from the DMDC using randomization to achieve representation of the women in the Air Force, and consequently, many of the women sampled were scattered on bases and locations all over the world. Further, many had moved and/or changed names (through marriage or divorce) and/or left the Air Force during the two years following the Persian Gulf war. It is primarily for these reasons that we could reach only 85 per cent of the women sampled. However, since the data-base tape provided by the DMDC included demographic and military status data on all of the women, we examined whether the characteristics of the non-respondents, the 113 women who did not provide data, differed systematically from the 525 respondents who provided data for the study. In this analysis, response rate was not related to marital status, parent status, years in the Air Force, or military rank. However, the respondents compared to the non-respondents were somewhat older (32 years versus 29 years). Of the subsample of white women, 87 per cent were respondents compared with 67 per cent of the subsample of minority women. And finally, of those deployed to the theater of operations, 89 per cent were respondents compared with 79 per cent of those deployed elsewhere.

\section{Results}

The means, standard of deviations and correlations among all the variables in the model are presented in Table 1. The figures in the diagonal are the reliability alpha coefficients. Except for the depression measure, all of our measures were identical to those used by Frone et al. (1992). While our measure of depression used 5-point scales, the one used by Frone et al. was the CES-D (Radloff, 1977) with 4-point scales. In another study we found that the CES-D measure had a correlation of 0.76 with our measure, which was about as high as the reliabilities of the measures would allow. Therefore, these measures could be considered equivalent measures of depression.

As expected, examination of the means of the variables in our women's sample compared with the means in Frone et al.'s (1992) representative community sample (c.f. Table 1 in the 1992 article) revealed that the Air Force women had higher levels of family stress, work-family work conflicts, and job distress. These means were higher by about one-third to one-half standard deviation. Given the size of the two samples, these differences are statistically significant. 
Table 1. Means, standard deviations, reliability estimates, and intercorrelations for major study variables

\begin{tabular}{|c|c|c|c|c|c|c|c|c|c|c|c|}
\hline Variable & 1 & 2 & 3 & 4 & 5 & 6 & 7 & 8 & 9 & M & S.D. \\
\hline 1. Job involvement & $(0.90)$ & & & & & & & & & 3.68 & 1.29 \\
\hline 2. Family involvement & 0.00 & $(0.92)$ & & & & & & & & 5.22 & 0.70 \\
\hline 3. Job stress & -0.09 & 0.03 & $(0.83)$ & & & & & & & 2.12 & 0.43 \\
\hline 4. Family stress & $0.12 *$ & $-0.38^{*}$ & 0.03 & $(0.82)$ & & & & & & 2.00 & 0.65 \\
\hline 5. $\mathrm{W} \rightarrow \mathrm{F}$ conflict & -0.02 & 0.03 & $0.33 *$ & $0.12 *$ & $(0.84)$ & & & & & 2.85 & 1.13 \\
\hline 6. $\mathrm{F} \rightarrow \mathrm{W}$ conflict & 0.05 & -0.05 & $0.18 *$ & $0.17 *$ & $0.37 *$ & $(0.75)$ & & & & 1.65 & 0.79 \\
\hline 7. Job distress & $-0.21^{*}$ & 0.01 & $0.70 *$ & 0.08 & $0.31 *$ & $0.17 *$ & $(0.83)$ & & & 2.10 & 0.64 \\
\hline 8. Family distress & 0.03 & $-0.54^{*}$ & 0.10 & $0.68 *$ & $0.19 *$ & $0.27^{*}$ & $0.13^{*}$ & $(0.93)$ & & 1.62 & 0.46 \\
\hline 9. Depression & 0.03 & -0.03 & $0.35^{*}$ & $0.26^{*}$ & $0.25^{*}$ & $0.24^{*}$ & $0.44^{*}$ & $0.33^{*}$ & $(0.86)$ & 1.65 & 0.55 \\
\hline
\end{tabular}

.

0
0
0
0
0
01
0
0
0
0
0
0
0
0
0
1
0
0
0
0
0
0

Note. Numbers on the diagonal are internal consistency reliability estimates (coefficient alpha).

$* p<0.05$. 


\section{Analytic strategy}

The principal analyses consisted of confirmatory latent-variable structural modeling using the EQS programme (Bentler, 1989). The structural modeling technique provides simultaneous estimation of the hypothesized regressions using the estimated covariance matrix generated, based on the observed covariance matrix of the measured variables. The estimated matrix is also used for evaluating the goodness-of-fit between the data and the model. In reporting the results of the structural equation modeling, we followed the guidelines suggested by Raykov, Tomer and Nesselroade (1991). With respect to examination of goodness-of-fit we followed Bollen's (1990) recommendation to report several different fit indices, both normed and non-normed. We therefore include Bentler and Bonnet's (1980) Normed Fit Index (NFI), Non-Normed Fit Index (NNFI), and Comparative Fit Index (CFI). Indices that exceed 0.90 are considered to provide acceptable fit. (For a detailed discussion of fit indices see Bentler, 1990, and Bollen, 1990.)

All of the analyses were performed separately on listwise and pairwise covariance matrices. The results were virtually the same. We therefore present the results from the pairwise matrices, which generated slightly better goodness-of-fit indices and are based on a larger portion of the original sample. Overall, missing data rates amounted to 15 per cent and, therefore, 85 per cent of the respective sample size was used as the actual $N$ in the EQS procedure.

Because we attempted to replicate the results of the model advanced by Frone and his associates, we followed all of their analysis procedures (for details, see Frone et al. [1992], pp. 70-71). Thus, we treated each multi-item scale as a single indicator for its corresponding construct; and, therefore, corrected for random measurement error by setting the random error variance associated with each construct equal to the product of its variance, and the quantity one minus its estimated reliability (Bollen, 1989). We also tested the same model as Frone et al. that included only the depressive symptoms as the main dependent variable and conducted separate tests of the expanded models that included both depressive symptoms and functioning as the main dependent variables.

\section{Testing the work-family conflict model}

Figure 1 presents the results of the structural equation parameter estimation of the general model offered by Frone et al. The data provide a very food fit to the model with $\chi^{2}(12$, $N=309)=28.53, p<0.004,{ }^{1}$ and with NFI $=0.96, \mathrm{NNFI}=0.93, \mathrm{CFI}=0.98$. The main contributors to depression were job distress and family distress ( $\beta=0.42$ and 0.27 , respectively). The stressors of each domain, job and family, contributed to the distress of the respective domain ( $\beta=0.79$ and 0.63 , respectively). Similarly, involvement in each domain reduced the distress level of each corresponding domain ( $\beta=-0.15$ and -0.36 , respectively for job and family). As workfamily conflict was affected only by job domain stressors $(\beta=0.29)$, family-work conflict was influenced by family domain stressors $(\beta=0.21)$. Work-family conflict and family-work conflict had a bi-directional influence on each other $(\beta=0.51$ and 0.50 , respectively). Finally, we found that work-family conflict influenced family distress $(\beta=0.16)$.

Overall, the findings provide a reasonably good replication of the model tested by Frone et al. Our structural analysis replicated 10 of the 13 significant directional paths that were found statistically significant by Frone $e t a l$. and an additional path from work-family to family distress

\footnotetext{
${ }^{1}$ Since even minute differences in a large sample tend to produce a statistically significant $\chi^{2}$, other measures such as the NFI, the NNFI and CFI, are used as indicators of goodness of fit.
} 


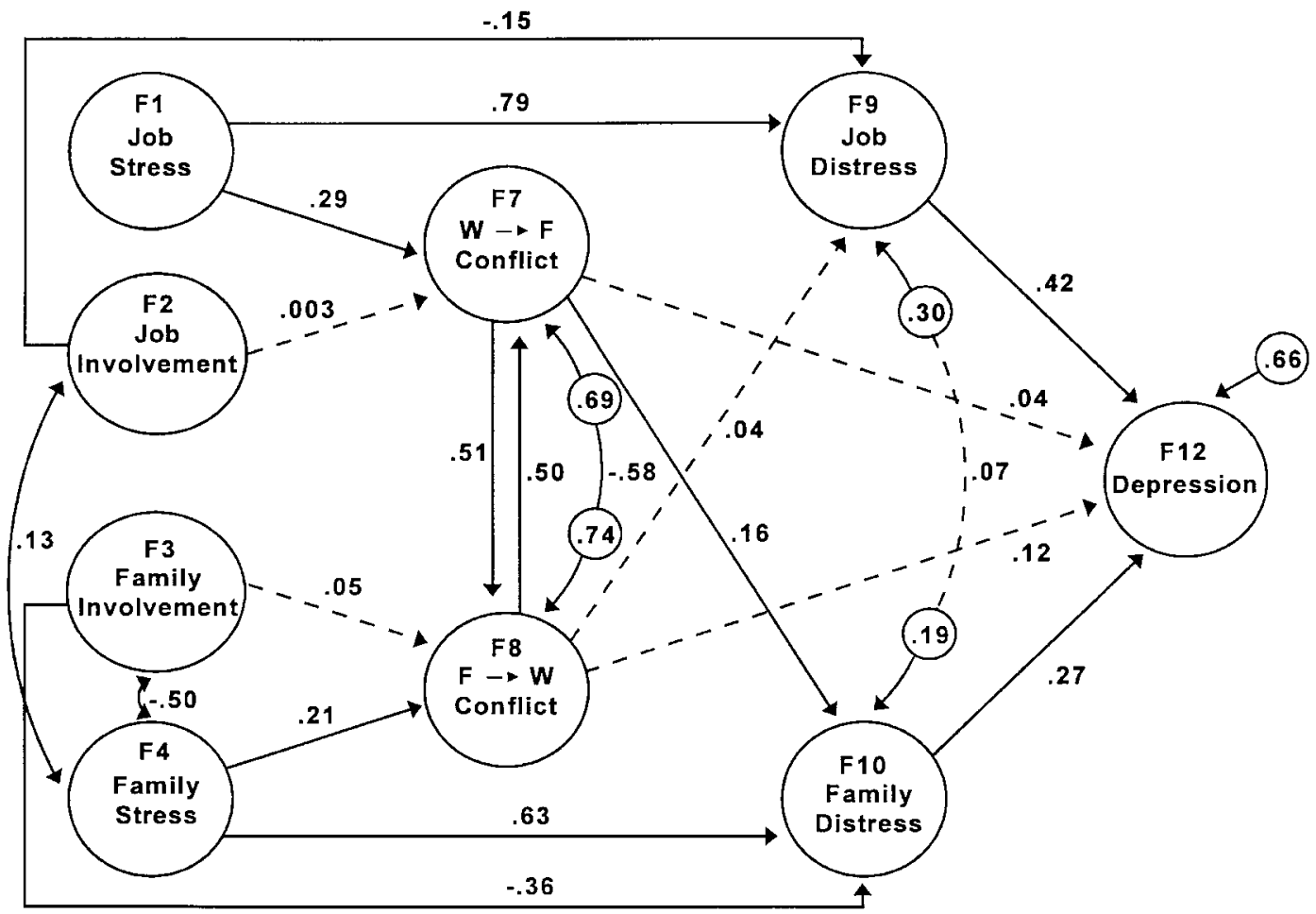

Figure 1. Standardized path coefficients representing effects of stress, distress and work-family conflicts on depression. $\chi^{2}(12, n=309)=28, p<0.004$ and NFI $=0.96$, NNFI $=0.93$, CFI $\left.=0.98\right)$. All the paths in solid lines are statistically significant at $p<0.05$. Numbers inside the small circles are residual variances.

that is part of the model but was not found statistically significant in Frone et al.'s analysis. Our analysis did not replicate the positive effect of family involvement on family-work conflict and the latter on job distress, or the effects of family-work conflict on job distress and depression.

We then tested the model described in Figure 1, adding role and emotional functioning as a separate dependent variable. The test resulted in a good fit to the model with $\chi^{2}$ (16, $N=309)=43.19, p<0.001$, and with NFI $=0.95, \mathrm{NNFI}=0.91, \mathrm{CFI}=0.97$. The main contributors to both depression and functioning were job distress $(\beta=0.42$ and -0.28 , respectively) and family distress ( $\beta=0.27$ and -0.32 , respectively).

Following our attempt to replicate the results of Frone et al. we tested a more detailed version of the model that included separate corresponding constructs for the parental and marital roles within the family. Thus, the model included constructs for the degree of involvement, the stress and the strain (distress) in the marital role (involvement, stress and strain in relationship with spouse/partner), and parental role. The results for the women who were both mothers and had a spouse or a committed partner are displayed in Figure 2. Again, the data provided a very good fit to the model with $\chi^{2}(25, N=180)=17, p<0.88$, and with $\mathrm{NFI}=0.98, \mathrm{NNFI}=1.00$, $\mathrm{CFI}=1.00)$.

As in the earlier model, the major contributor to depression is job distress $(\beta=0.45)$ and, in addition, relationship distress $(\beta=0.31)$, but not parental distress. In this model, as in Frone et al. family-work conflict is also a significant contributor to depression $(\beta=0.21)$. Each domain of distress was found to be affected by its corresponding stressor $(\beta=0.88,0.60$, and 0.64 , respectively for jobs, relationship, and parenting). As seen in the earlier model, the level of 


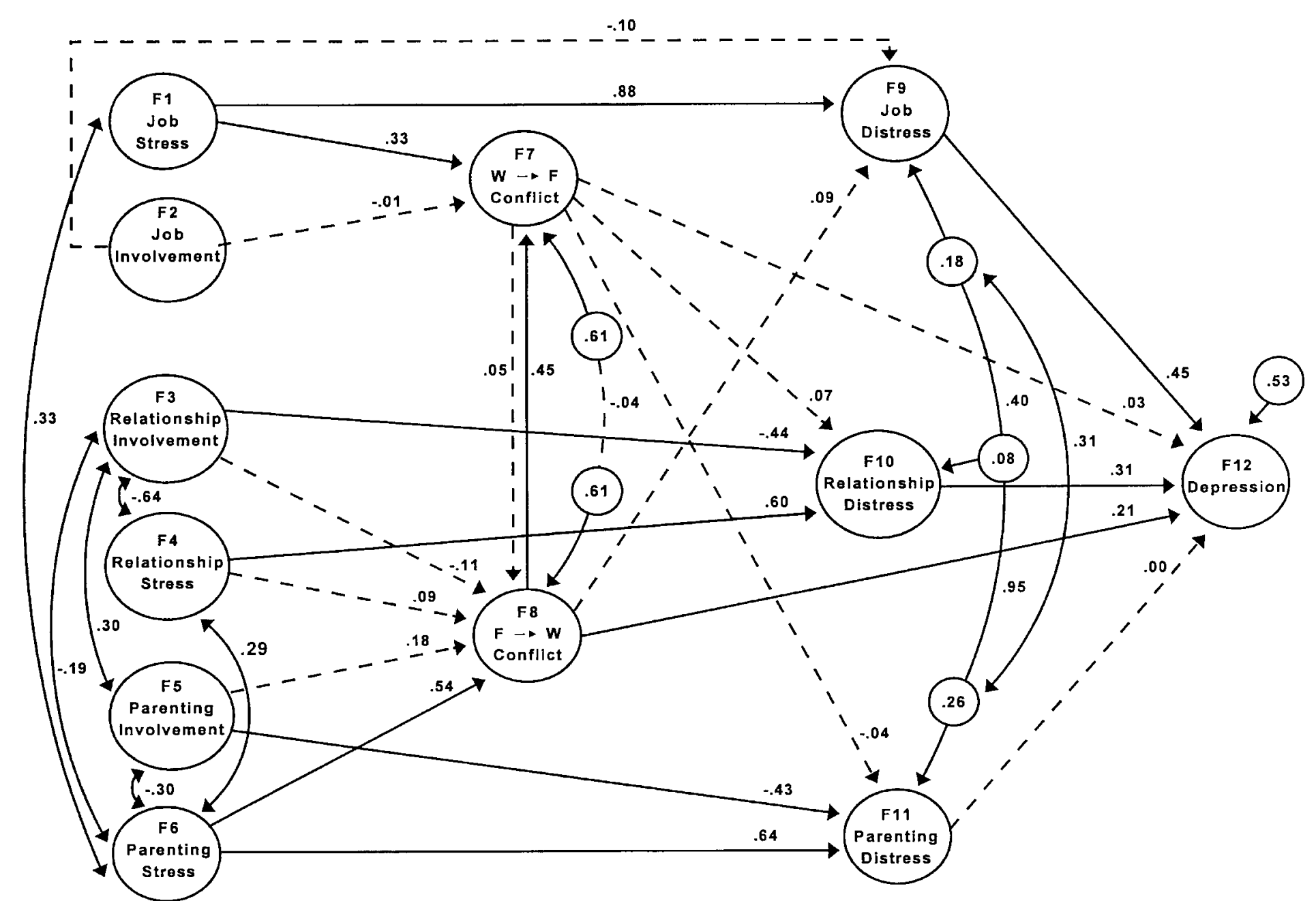

Figure 2. Standardized path coefficients representing effects of stress and distress in job, marital and parental domains on work-family conflicts and depression. $\chi^{2}(25, n=180)=17, p<0.88$ and NFI $\left.=0.98, \mathrm{NNFI}=1.00, \mathrm{CFI}=1.00\right)$. All the paths in solid lines are statistically significant at $p<0.05$. Numbers inside the small circles are residual variances. 
involvement in each domain was not associated with work-family or family-work conflict but had a beneficial effect in reducing the corresponding distress levels $(\beta=-0.10$, one-tail, -0.44 , and -0.43 , respectively for involvement in job, relationship, and parental domains). Again, as seen in the earlier model, job stress had an impact on work-family conflict $(\beta=0.33)$. Yet, only parental stress had an adverse impact on family-work conflict $(\beta=0.45)$. Finally, and in sharp contrast to the results of the earlier model that showed bi-directional effects between workfamily and family-work conflict of equal size, the current model shows only a unidirectional influence that goes from family-work conflict to work-family conflict $(\beta=0.45)$.

Again we tested the model described in Figure 2 adding role and emotional functioning as a separate dependent variable. The test resulted again in a very good fit to the model with $\chi^{2}(31$, $N=180)=26.77, p<0.68$, and with $\mathrm{NFI}=0.97, \mathrm{NNFI}=1.00, \mathrm{CFI}=1.00$. The main contributors to both depression and role and emotional functioning were job distress $(\beta=0.46$ and -0.33 , respectively), relationship distress $(\beta=0.31$ and -0.18 , respectively), and parental distress for role and emotional functioning $(\beta=-0.25)$, but not for depression.

\section{Discussion and conclusions}

We attempted to replicate the work-family conflict model published by Frone et al. (1992) and our results are very similar to the original test of the model. The replication of these results extends to an additional measure assessing role and emotional functioning. Thus, the results based on the measure of depressive symptoms, as well as on functioning, are more broadly indicative of the effects of the various stressors and strains on mental health and well-being than those based on any one specific measure.

Whereas the result of the model by Frone et al. was based on a representative community survey of both male and females respondents, our results are based on a representative stratified sample of women who were enlisted in the Air Force during the Gulf War. In the Frone et al.'s (1992) test of their model, family-work conflict was a significant determinant of job distress and of depression. In our test of the model, we did not replicate this effect. Instead, we found that work-family conflict was a significant determinant of family distress. These differences in the results of the two studies may be due to any number of demographic or life-style differences between the samples. For example, mean age of respondents in Frone et al.'s (1992) sample was 40.7 compared to 33.9 in our sample. The age difference itself is indicative of other differences, such as mean number of dependent children and their ages, which may have an impact on workfamily conflicts and other variables.

Our extended model separated overall family stress into marital relationship stress and parental stress (Figure 2). It demonstrated that for women who play both parenting and occupational roles, it is the parental stress that produces the family-work conflict. In turn, the family-work conflict increases depression. That is, for the women who play both roles, the effects of parenting stress on depression are mediated through the effects of the parenting stress on family-conflict. In contrast, the effects of relationship stress on depression are mediated through their effects on relationship distress, which in turn, increases depression, much the same way job stress increases depression through its effects on job distress. And finally, although parenting distress was not found to increase depression, it was found to decrease role and emotional functioning.

The more differentiated results that emerged when the marital and parental roles are separated in this analysis illustrate the different pathways through which parental stressors, as contrasted 
with job and relationship stressors, affect the well-being of military women. The different pathways could suggest more specific interventions that are needed to address the special needs of mothers in the military. For mothers, their parenting role is the primary stressor that influences family-work conflict, which in turn has negative effects on depression and functioning. Support services that reduce the parental stress directly, such as supportive child-care arrangements for mothers, or at least reduce the family-work conflict, are likely to interrupt the cascade of disruptive influences that these variables have on women's mental health.

Finally, none of the three types of role involvement - job, marital, and parental involvementwas found to increase work-family or family-work conflicts. In turn, the results suggested that all three types of role involvement reduce distress, which is also shown to reduce the level of depression. Institutional norms and supportive services that help women to maintain strong involvement in marital and parental roles do not compete with their job involvement and do not create work-family conflicts; instead, they help to reduce the level of distress in these roles and improve mental health. Furthermore, the negative correlations in the family domain found between level of stress and involvement suggest that programmes that reduce stress may increase involvement and vice versa. Further research could identify more precisely the kind of work environment norms and services that could reduce the level of stress in the various roles and those that promote role involvement, as both outcomes are beneficial to women's mental health.

\section{References}

Adams, G. A., King, L. A. and King, D. W. (1996). 'Relationships of job and family involvement, family social support, and work-family conflict with job and life satisfaction', Journal of Applied Psychology, 81, 411-420.

Barling, J. and Macewen, K. E. (1992). 'Linking work experiences to facets of marital functioning', Journal of Organizational Behavior, 13, 573-583.

Bentler, P. M. (1989). EQS Structural Equations Program Manual, BMDP Statistical Software, Los Angeles, CA.

Bentler, P. M. (1990). 'Comparative fit indexes in structural models', Psychological Bulletin, 107, 238-246.

Bentler, P. M. and Bonett, D. G. (1980). 'Significant tests and goodness-of-fit in the analysis of covariance structures'. Psychological Bulletin, 88, 588-606.

Berardo, D. H., Shehan, C. L. and Leslie, G. R. (1987). 'A residue of tradition: jobs, careers, and spouses' time in housework', Journal of Marriage and the Family, 49, 381-390.

Bey, D. R. and Lange, J. (1974). 'Waiting wives: women under stress', American Journal of Psychiatry, 131, 283-286.

Bielby, D. D. (1992). 'Commitment to work and family', Annual Review of Sociology, 18, 281-302.

Biernat, M. and Wortman, C. B. (1991). 'Sharing of home responsibilities between professionally employed women and their husbands', Journal of Personality and Social Psychology, 60(6), 844-860.

Bollen, K. A. (1989). Structural Equations with Latent Variables, Wiley, New York.

Bollen, K. A. (1990). 'Overall fit in covariance structure models: two types of size effects', Psychological Bulletin, 107, 256-259.

Caplan, R. D., Abbey, A., Abramis, D. J., Andrews, F. M., Conway, T. L. and French J. R. P. Jr. (1984). Tranquilizer Use and Well Being: A Longitudinal Study of Social and Psychological Effects. (Technical Report Series), Institute for Social Research, Ann Arbor.

Dahl, B. B., McCubbin, H. I. and Ross, K. L. (1975). 'Second generational effects of war-induced separations: comparing the adjustment of children in reunited and non-reunited families', Military Medicine, 142(2), 146-151.

Derogatis, L. R., Lipmann, R. S., Rickels, K., Uhlenhuth, E. H. and Covi, L. (1974). 'The Hopkins Symptoms Checklist (HSCL): a measure of primary symptom dimensions', In: Pichot, P. (Ed.), 
Psychological Measurements in Psychopharmacology. Modern Problems in Pharmacopsychiatry, Vol. 7, pp. 79-110, Pasel, Karger.

Frone, M. R. and Rice, R. W. (1987). 'Work-family conflict: the effect of job and family involvement', Journal of Occupational Behavior, 8, 45-53.

Frone, M. R., Russell, M. and Cooper, M. L. (1992). 'Antecedents and outcomes of work-family conflict: testing a model of the work-family interface', Journal of Applied Psychology, 77(1), 65-78.

Holm, J. (1992). Women in the Military: An Unfinished Revolution, Presidio Press, Novato, CA.

Jensen, P. S., Lewis, R. L. and Xenakis, S. N. (1986). 'The military family in review: context, risk, and prevention', Journal of American Child Psychiatry, 25, 225-234.

Kandel, D. B., Davies, M. and Raveis, V. H. (1985). 'The stressfulness of daily social roles for women: marital, occupational and household roles', Journal of Health and Social Behavior, 26, 64-78.

Kanungo, R. N. (1982). 'Measurement of job and work involvement', Journal of Applied Psychology, 67, 341-349.

Kessler, R. C. (1985). '1985 Detroit area survey’, Unpublished questionnaire, University of Michigan, Institute for Social Research, Ann Arbor.

Kupchella, D. L. (1993). 'Social policy and planning and legislative considerations', In: Kaslow, F. W. (Ed.), The Military Family in Peace and War, Springer, New York.

Lennon, M. C. and Rosenfield, S. (1992). 'Women and mental health: the interaction of job and family conditions', Journal of Health and Social Behavior, 33, 316-327.

MacIntosh, H. (1968). 'Separation problems in military wives', American Journal of Psychiatry, 125, 260-265.

Matthews, K. A. and Rodin, J. (1989). 'Women's changing work roles: impact on health, family and public policy', American Psychologist, 44, 1389-1393.

Menaghan, E. G. (1991). 'Work experiences and family interaction processes: the long reach of the job', Annual Review of Sociology, 17, 419-444.

Nunnally, J. C. (1978). Psychometric Theory (2nd ed.), McGraw-Hill, New York.

Radloff, L. S. (1977). 'The CES-D scale: a self-report depression scale for research in the general population', Applied Psychological Measurement, 1, 385-501.

Raykov, T., Tomer, A. and Nesselroade, J. R. (1991). 'Reporting structural equation modeling results in psychology and aging: some proposed guidelines', Psychology and Aging, 6, 499-503.

Repetti, R., Matthews, K. A. and Waldron, I. (1989). 'Employment and women's health: effects of paid employment on women's mental and physical health', American Psychologist, 44(11), 1394-1401.

Schneider, D. and Schneider, C. J. (1992). Sound off! American Military Women Speak Out, Paragon House, New York.

Segal, M. W. (1986a). 'Enlisted family life in the U.S. Army: a portrait of a community', In: Segal, D. R. and Sinaiko, H. W. (Eds.), Life in the Rank and File: Enlisted Men and Women in the Armed Forces of the United States, Australia, Canada, and the United Kingdom, Pergamon-Brassey's International Defense, Washington D.C.

Segal, M. W. (1986b). 'The military and the family as greedy institutions', Armed Forces and Society, 13(1), 9-38.

Segal, M. W. (1989). 'The nature of work and family linkages: a theoretical perspective', In: Bowen, G. L. and Orthner, D. K. (Eds.), The Organization Family: Work and Family Linkages in the U.S. Military, Praeger, New York.

Stanley, J., Segal, M. W. and Laughton, C. J. (1990). 'Grass roots family action and military policy responses', Marriage and Family Review, 15(3/4), 207-223.

U.S. Bureau of the Census. (1988). 'Household and family characteristics: March 1987', Current Population Reports, Series P-20, No. 424.

U.S. Bureau of the Census. (1990). Statistical Abstract of the United States: 1990, 110th Edition. U.S. Government Printing Office, Washington, D.C.

U.S. Presidential Commission. (1993). Women in Combat: Report to the President, Brassey's, Washington.

Vinokur, A. and Caplan, R. D. (1987). 'Attitudes and social support: determinants of job-seeking behavior and well-being among the unemployed', Journal of Applied Social Psychology, 17(12), 1007-1024.

Wexler, H. K. and McGrath, E. (1991). 'Family members stress reactions to military involvement separation', Psychotherapy, 28(3), 515-519.

Wortman, C. B., Biernat, M. and Lang, E. (1991). 'Coping with role overload', In: Frankenhauser, M. (Ed.), Women, Work and Health: Stress and Opportunities, pp. 85-110, University of Chicago Press, Chicago. 